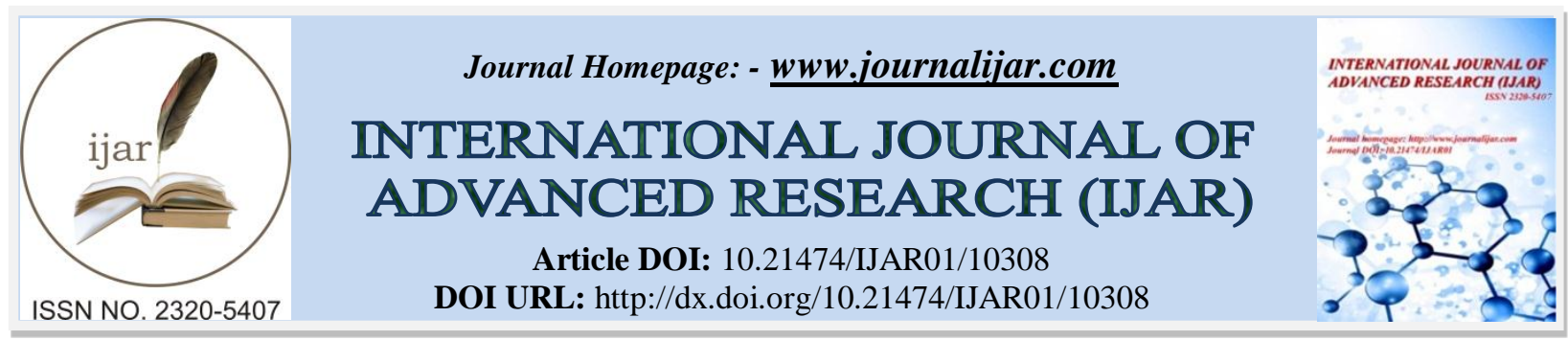

RESEARCH ARTICLE

\title{
GLOBALIZATION AND ITS IMPLICATIONS ON EDUCATION IN THE CONTEXT OF THE KINGDOM OF SAUDI ARABIA
}

1. Ministry of Education, Riyadh 12435.

Rfah Alyami ${ }^{1}$, Nouf Alajmi ${ }^{2}$ and Aishah Alkahtani ${ }^{1}$

2. Imam Mohammed Bin Saud University.

\section{Manuscript Info}

Manuscript History

Received: 25 November 2019

Final Accepted: 27 December 2019

Published: January 2020

Key words:-

Globalisation, Neoliberalism, School

Reform, Saudi Arabian vision 2030

\section{Abstract}

It is thought that neoliberalism as a driver of globalization presents a promise of welfare and benefit for societies, opponents claim that this theory in general seems to threaten the identity, language and beliefs of countries, and also would benefit the interests of the West in particular more than developing countries. This view is supported by critics in the Saudi context where scholars such as Alghathami argue that neoliberalism seeks to impose a holistic perception of culture in favour of the strong and dominant nations. He believes that this domination has negative consequences on economic and social factors. This study describes the impact of globalization on the educational system in Saudi Arabia.

Copy Right, IJAR, 2020,. All rights reserved.

\section{Introduction:-}

The aim of the paper is to describe the impact of globalization on the educational system in Saudi Arabia. The paper is divided into two sections. The first section discusses the concept of globalization. The argument is that there are two opposing views about globalization. The first perceives globalization linked with neoliberal economic theory as a positive development. Neoliberal economic theory places emphasis on the primacy of the market as the key regulatory mechanism. As such, free-market ideology has also been applied to the social arena including healthcare and education. "Advocates of global neo-liberalism argue that the prevailing system of development will result in economic growth, employment, affordable quality goods and service, and a reduction in world poverty" [2]. The second argument is more critical about globalization and argues from a cultural and social perspective that:

Neoliberalism tends to treat economics in isolation from other dimensions of social relations. In particular, the doctrine supposes that economic policies toward globalization could be a culturally and politically neutral matter of technical expertise [3].

These two arguments will be discussed more critically in this study with special reference to the impact of globalization on non-western societies such as Saudi Arabia. Therefore, the main question of this study is: What is the impact of globalization on the educational system in the Kingdom of Saudi Arabia?

The main research question will be discussed in this study, where globalization has had a significant impact on education worldwide and as a result governments sought to reform their educational systems.

Corresponding Author:- Rfah Alyami

Address:- Ministry of Education, Riyadh 12435. 


\section{What is globalization?}

Although it is not a new phenomenon, the term "globalisation" has been used increasingly since the 1980s. However, its origin can be traced to long before the modern era [4]. There are a variety of definitions of the concept of globalization. Adams (2011) argues that:

Globalization has been the catchword of the late $20^{\text {th }}$ and early $21^{\text {st }}$ century. It refers to the growing integration of the world, linking together into one global whole what had, heretofore, been independent activity centers all over the world. Globalization is an ongoing process. Although the world is becoming smaller as trade barriers are reduced and as communications and transportation improve... the world becomes more integrated; it is said to become more "globalized". The term globalization has important economic, political, social, and cultural dimensions (Adams, 2011, pp.3-4)

This view suggests that globalization is an on-going process that integrates activities worldwide into one global world through communications and transportation and shrinking distances. Held, McGrew [6] identify three dimensions of global interconnectedness. They state that:

Globalization refers to the widening, deepening and speeding up of global interconnectedness... Globalization can be taken to refer to those spatio-temporal processes of change which underpin a transformation in the organization of human affairs by linking together and expanding human activity across regions and continents. Without reference to such expansive spatial connections, there can be no clear or coherent formulation of this term [6].

Held, McGrew [6] definition emphasises the relationship between human activities and processes with regard to the spatial, which are concerned with time and space as well as the global scale of expanding and deepening of such connections. Giddens [7] provides further explanation in his argument that:

Globalization can thus be defined as the intensification of worldwide social relations which link distant localities in such a way that local happenings are shaped by events occurring many miles away and vice versa. This is a dialectical process because such local happenings may move in an obverse direction from the very distanciated relations that shape them. [7]

Giddens [7] underlines the distant local relations of the world and social ties intensification, which is similar to the previous emphasis by Held, McGrew [6] although he identifies greater complexity. Adams (2011) view is focused on reducing trade barriers to link the world globally. In other words, globalization can be viewed as a compressed world, which makes the world an interconnected place.

The next section will discuss the opposing views of globalization from an economic and sociocultural perspective; this includes, the impact of globalization on cultural, social, educational and economic aspects of countries.

\section{Views of globalization: \\ Economic view of globalization: \\ Neo-liberalism:}

As stated above, neoliberal theory places emphasis on the free-market economy and considers education a significant business and investment [8]. Kotz [9] argues that:

Neoliberalism is both a body of economic theory and a policy stance. Neoliberal theory claims that a largely unregulated capitalist system (a free market economy) not only embodies the ideal of free individual choice but also achieves optimum economic performance with respect to efficiency, economic growth, technical progress, and distributional justice [9].

According to neoliberal theory the legal regulatory framework has to support and facilitate private ownership with limited public control and accountability [3,9] with a balance of liberalization, privatization and deregulation, hoping that globalization would benefit civilization in peace, human security, social justice democracy and liberty. There are many complexities within societies that impact on their ability to compete in the global economy. Scholte [3] provides some indications of these complexities in his argument that:

Privatization, liberalization and deregulation remain the order of the day, but these core neoliberal policies are now undertaken in tandem with more measures that address corruption, transparency, financial codes and standards, 
unsustainable debt burdens, the timing and sequencing of capital control removal, social safety nets, poverty reduction, corporate citizenship and so on. [3]

Indeed it has been argued that neoliberalism represents an advocate of exploitation of the majority in favour of the economic elite; where it serves to concentrate global profit in the hand of rich countries, in particular the United States [10].

However, it could be argued that neoliberalism would have been more useful if it had created market access for poor people by increasing access to education, land and micro-finance in addition to enhancing regulation [10]. Moreover, whilst neoliberalism presents a promise of welfare and benefit for societies, opponents argue that this theory in general seems to threaten the identity, language and beliefs of countries, and also would benefit the interests of the West in particular more than developing countries.

Impact of globalization on economy

Increasing investment, trade, and migration worldwide affect employees directly in developed and developing nations [8]. It has been argued that:

Despite the decline in the manufacturing wage, all workers see an increase in their expected discounted lifetime utility as a consequence of liberalization. While it is true that the manufacturing wage declines, wages in other sectors rise. All workers have a positive probability that they will move to one of those higher paying jobs [11].

Spence and Leipziger [11] argue that the impact of globalization on the economy has reduced poverty in many developing nations; they also state that:

Globalization as an economic phenomenon has been the dominant force for economic integration and the main driver of growth worldwide for many decades, although the speed of globalization - taken to include trade, finance, flows of information and technology, and offshoring - is unprecedented in modern economic history [11].

It seems that global trade, migration and liberalization have an impact on reducing poverty and increasing growth worldwide.

On the other hand, "Inequality...also changes opportunities, incentives, and institutions that form, develop, and transmit characteristics and skills valued in the labor market" [12] would increase the poverty of some disadvantaged groups. Moreover,

It could be argued...that inequality of opportunity acts for many as a barrier to fulfilling their potential. Those disadvantaged do not forego education because of a lack of incentives in terms of higher pay for the more educated, but because of a range of barriers to their doing so ... A stress on reducing inequality of opportunity leads to policies designed to change the distribution of abilities to compete and to make education more egalitarian; but these policies accept that competition will generate inequalities of income, wealth and outcomes [10]

Competition is an important element in neoliberal theory; as argued earlier, it has a negative impact on the equality of opportunities. In the context of Saudi Arabia, women are more likely to have fewer work opportunities and also less income compared to Saudi males. Alnajem [13] found that poor women in Saudi Arabia suffer from a low level of education. Lack of employment opportunities, she argues, is due to social and cultural factors that interact with each other to influence women's experience making them victims of poverty.

However, Aksornkool [14] argues for the importance of making a supportive political decision to empower women's status. It is insufficient on a large scale to empower women only in education, as this political decision would create a regulation that impacts on society's attitude towards women and accelerates their empowerment.

The two arguments presented here are contradictory; the first is more positive and has perceived that the impact of globalization on the economy has reduced poverty, as globalization is the main driver of growth in the worldwide. The second argument appears to be negative and perceives globalization represented in neoliberalism as a catalyst for competition between individuals, which would increase the issue of inequality of opportunity. 


\section{The next section will discuss the social and cultural views on globalization: Cultural and social views of globalization:}

Globalization affects culture in a way that, when people of different classes and cultures come together to share their ideas, they begin to get to know each other. Thus, globalisation is a social process in which people with different backgrounds interact. This combination of cultures in all spheres of life exposes people to different attitudes and new ways of thinking. Business networks enable nations to know more about each other; however, local cultures are most affected by television, newspapers and other media channels. Conversely, people who migrate to, and settle in, other countries are more open to cultural change. As more and more people are gaining access to the Internet, communication between people has increased with the shortening of time and distance [15]. Nevertheless, the threat of losing national and ideological identity because of globalization is a concern in a religious and conservative country such as Saudi Arabia. Alghathami [1] argues that Muslims are more likely to support Saudi Arabia to keep its privacy and conservation as a country that provides religious direction for Muslims worldwide. However, it could be argued that exclusiveness would not fit the universal mission of the Qur'an and its values. Nurullah [16] also maintains that:

Globalisation poses a challenge to Islamic culture and identity because globalisation promotes the transmission of information through the media and this has resulted in the dominance and hegemony of Western culture over the rest of the world. This poses a challenge to Islamic ways of life, values, and principles. However, as globalisation is inevitable, Muslims should take the benefits and opportunities provided by globalisation in spreading and demonstrating the unique traits of Islamic cultural identity around the world through various means [16].

With the advancement in the communication networks of governments and local people, changes have been implemented in human resource development, which have resulted in the introduction of new ideas of educational policies and improvements in industrial production outputs [15]. "Over the years, for many people these changes have been beneficial, increasing knowledge, advancing technology, raising income" (Adams, 2011, p. 6). Educational practices, policies and organisations are also influenced largely by the global changes taking place [17].

\section{Impact on education:}

The impact of globalisation on educational systems and practices is deep rooted and conflicting. Much-needed reforms can be observed in the collaboration of the UNESCO and UN agencies. This includes: equal education for all; universal educational practices and policies; education as a basic human right; education for the wellbeing of the economy; education for the awareness of a better environment; education about how to participate in governmental systems; and continuous development of new technology and infrastructure [17]. However, "The striking evidence laid out ... demonstrates not only education's capacity to accelerate progress towards other development goals, but also how best to tap that potential, most of all by making sure that access to good quality education is available to all, regardless of their circumstances" [18]. In line with this over the last three decades, local school systems have focused on developing education as the key to economic improvement and the creation of competitive advantage over other economies. Many countries within the UN are working together to provide equal primary and secondary education worldwide. The rise of this global education is shaping the structure from ordinary citizens to global citizens. As a result of globalisation, many developing countries have experienced improvement in their local school systems through facilities provided by global educational institutions [15].

It is argued that, "neoliberal efforts in education aim at reorganizing schooling so the needs of the local and global economy are met by producing human capital" [19]. Introducing the policy of neoliberalism has led to create one single educational policy, practices and their respective curricula and equal acceptance of this system worldwide [15]. However, opponents suggest that diversity in nations would not benefit from neoliberalism policy in education.

Globally, countries are struggling with problems that have not been faced by earlier generations. National schooling systems are undergoing continuous change as a consequence of the effects of globalisation.

Governments in developing nations have faced pressure to increase spending on education. This pressure was as a result of the need to have more educated workers. The argument is that a more educated labour force attracts global capital, which in turn impacts positively on the economy. However, as a result of neoliberal economic policy influences governments have been forced to encourage other sources to fund education and limit public spending [20]. Misra and Bajpai [21] explain the notion of the movement to limiting public spending. They state that: 
In several countries, they were expressed in the adoption of neo-liberal economic policies; they led to attempts to cut public expenditure, and to maximize the economic benefits of educational spending by increasing its efficiency and directing its goals to economic rather than social or cultural ends [21].

Another global impact on education is that two international testing programmes are used to measure performance and enable global politicians to discuss the existing gaps in the universal educational system: The International Mathematics and Science Survey (TIMSS) and The Program for International Student Assessment (PISA). These organizations share an opinion regarding how education is provided. They hypothesize an education for the improvement of the economy, which fulfils the expectation of skilled labour demands within a single global economy [22]. The findings of PISA, for example;

Allow policy makers around the world to gauge the knowledge and skills of students in their own countries in comparison with those in other countries, set policy targets against measurable goals achieved by other education systems, and learn from policies and practices applied elsewhere. While PISA cannot identify cause-and-effect relationships between policies/practices and student outcomes, it can show education, policy makers and the interested public how education systems are similar and different- and what that means for students [23].

However, "It is argued that the influence of PISA may jeopardize the democratization of education policy insofar as it allows elites to pursue their own agendas with little public input" [24]. The effects of globalizing education are the most moral values that are related to the cultural and social factors seem to be ignored.

On the other hand, where viewing the neoliberal education as an economic catalyst to reform education, it is believed that "educational institutions in Saudi Arabia are expected to cater for the new market and to create a more competitive market for the students to flourish in their creativity" [19]. However, Rugh [25] and Prokop [26] argue that the style of teaching at schools takes the shape of rote learning; it ignores using new learning approaches such as discussion between students and teachers, collaboration and creative thinking as well as the centralised control system.

\section{The next section discusses school reform as one of the main outcomes of globalization: School Reform:}

Improving the quality and access to education is a priority in many countries to achieve school effectiveness. It is believed that most research concerned with school effectiveness uses students' results as the indicator of quality [27].

As stated earlier, the value of international learning assessments such as the Trends in International Mathematics and Science Study (TIMSS), Education Management Information Systems (EMISs), and Program for International Student Assessment (PISA) have been appreciated, where many countries have participated in nationally and internationally benchmarked assessments. The data from these international assessment programs are useful to leverage change for better learning outcomes and improved service delivery [28]. However, "the debate about standards has gone global, with both government and opposition parties seeking to strengthen their arguments with international examples" [29]. Moreover, there is a real concern in the literature with the standards, as education is more complex than the result of the examination. In addition, it has emphasised the concern of value for money in education [30], where investing in education is the main factor that affects the economic growth. Mainly, "government(s) struggled to develop new education policies that would, they hoped, be both less costly and more effective" [31]. Haddad, Carnoy [32] state that:

Educational investment has been one of the most important factors contributing to economic growth; that expenditures on education contribute positively to labor productivity; that the economic payoff to spending on education from both a private and public standpoint is high, in absolute terms and compared to other investments [32].

The demand for investment in education is strongly indicated by stakeholders worldwide. However, there is little evidence that the capability of the existing educational system's policies will produce higher performance (Harris et al., 2003). Since the 1980s, enhancement in the quality of education have been pursued through policies and reforms on at least three common grounds: standardisation of education, greater focus on literacy and numeracy, in order to improve student achievement; and ensuring rigorous accountability of schools [34, 35]. 
The example of school reform addressed in this research relates to the 2030 vision. The reasons for reforming education in Saudi Arabia vary; there are both external and internal demands. Further, external challenges are represented in globalization, global competition, maintenance of the culture and the information revolution. In contrast, internal challenges are represented in a broad geographic area; divergent population; population growth; reliance on oil as a main economic source; educational environment; educational culture; and the teaching profession. Moreover, the education system tends to be centralised where the fiscal and administrative authority can be found within the Ministry of Education. By doing this, schools and educational administrations in each region are not equipped to develop or confront any urgent challenges. Another important challenge was the level of student achievement, which was poor compared with their counterparts in other countries, according to (TIMSS) in Maths and Science. There is also a lack of scientific criteria from which to judge schools' performance, quality and outcomes [36]. All these challenges are considered plausible reasons to rethink the actual system and attempt to reform and upgrade its standards.

Generally, to reform the education in large-scale, governments tend to deal with common factors such as curriculum, accountability, governance, market forces, and status of teachers (Hopkins \& Levin, 2000). Bruns, Filmer [28] argue that new reforms have to be subjected to rigorous evaluation to investigate their impacts on cost-effectiveness, which help to strengthen accountability to examine whether these reforms have achieved the desires goal and who benefit and at what public cost. They state that:

Governments universally mediate the market for education because the sector suffers from a set of market failures that government intervention can rectify. As a result, the users of education services — parents and children - are also principals trying to ensure that their country's Ministry of Education establishes a system that produces the highquality education they demand. This sequential set of principal-agent problems demands a more complex system of incentives and accountability [28].

However, there are many challenges that face educational reform internationally; the major and more important is embracing globalization [38]. These educational movements in the era of globalisation, however, would affect education sectors in nations worldwide. As a developing country, Saudi Arabia is attempting to adopt the best practices and models nationally and internationally, in order to reform its education system, by introducing different schemes and projects. One of these projects is the vision 2030 as a significant scheme to reform the economy and enhance the level of welfare in the country.

\section{Methodology:-}

For the purpose of analysis, this study adopted a qualitative methodology, i.e. interviewing the participants by the way of open ended questions. This study has been developed by extending one chapter from unpublished thesis, and was conducted on March 2017 for more than three months. As the part of the qualitative study, interviews were organized with 23 participants who are working within different profiles in the educational industry of Saudi Arabia. Those participants were interviewed all of whom were associated with the education industry in different ways such as being educational supervisors of different subject areas, Headteachers, professors. All the participants who were interviewed were highly qualified and experienced individuals. The major advantage of this method is that all the participants can freely voice their opinions against the demanding questions, without the interruption of the researchers. Various questions relating to the impact of globalization on the economy, education, teaching and learning methodologies etc. were asked along with the questions on government initiatives in this respect and the efficacy of the same. The collected data is then analyzed by adopting thematic content analysis method, where relevant themes are derived from the responses and interpreted to reach the desired conclusions. The stepwise methodology given by Braun and Clarke [39] has been used to conduct the analysis and to identify themes. Therefore, the present study follows an interpretive approach to answer the research questions. The analysis was conducted by following the below steps:

\section{Become familiar with the data:}

The initial step in the qualitative analysis is reading, and understanding the transcripts. One needs to be very familiar with the entire body of data or data collection (i.e. any data you may be using and the data relevant to all the interviews) before proceeding. At this step, it is beneficial to make notes and record the first opinion. 


\section{Generating initial codes:}

In this stage, we begin to organise our data in a significant and orderly manner. Coding reduces lots of data into small chunks of relevant information. Each segment of data was coded that was relevant to or that captured something unique about the research questions of this research. Every piece of text was not coded. Open coding was used in this study; that means pre-set codes had not been there, but the codes were developed and modified as work through the coding process was done.

\section{Searching and Defining Themes:}

After the formation of initial codes, the major themes and sub-themes of the study are identified by collating the initial codes into potential themes. The codes which were not relevant to the study are removed in this stage. The following table demonstrates the themes identified from the participant's opinions and relevant research questions, along with its corresponding sub-heads. The last theme, i.e. the economic impact of globalization was removed at this stage as the responses received discussed majorly the economic impacts of globalization alone abandoning the main variable of our research, i.e. its impact on education. Hence, this theme was considered unnecessary taking into account the aim of the present study.

Table 1:- Major themes and sub-themes.

\begin{tabular}{|c|c|c|}
\hline S. No & Themes & Subthemes \\
\hline \multirow[t]{5}{*}{1} & \multirow{5}{*}{$\begin{array}{l}\text { Positive impact of globalisation on } \\
\text { education }\end{array}$} & Easy and quick spread of Information \\
\hline & & Enhancement of knowledge \\
\hline & & Development of teaching methods \\
\hline & & Intellectual and cultural unification \\
\hline & & Universal homogeneity \\
\hline \multirow[t]{4}{*}{2} & \multirow{4}{*}{$\begin{array}{l}\text { Negative impact of globalisation on } \\
\text { education }\end{array}$} & integration of foreign culture \\
\hline & & Challenges in terms of curricula \\
\hline & & learners who need more efforts to maintain their ideas and identity \\
\hline & & countries that are politically superior \\
\hline \multirow[t]{3}{*}{3} & \multirow[t]{3}{*}{ Social and cultural Impact } & Impact on Identity \\
\hline & & Impact on culture \\
\hline & & Impact on the thought process \\
\hline \multirow[t]{3}{*}{4} & \multirow{3}{*}{$\begin{array}{l}\text { Government plans in promoting } \\
\text { globalisation in Education }\end{array}$} & Plans by Ministry of education \\
\hline & & Vision 2030 \\
\hline & & Fattan \\
\hline
\end{tabular}

\section{Interpretation and Analysis of themes- Producing Report: Positive Impact of globalization on education:}

The study identified various aspects in which globalization impacts education in Saudi Arabia. Some of the participants presented positive views on its impact, some negative and some others presented mixed views on the area amongst the positive impacts, one major positive change that globalization has brought about as per the participants is that it has enabled easy spread of global information, i.e. the information is now easily available across boundaries and is not merely confined within the political boundaries of the nations. Spring (2009) reported that the advantage of using the internet results in the ease of free communication between others. Judging from the results obtained from the research fieldwork as quoted by one of the interviewee "globalization facilitate having ideas and information easily and quickly from different sources around the world" and also, not only the spread of information is fast but it is simultaneously adaptive in nature in the sense that one can keep up to date with the latest information in the field of education at all times and the changes can therefore be implemented within own economy, besides, globalization also aids in enhancement of information wherein it can "Contribute to enhance moral, spiritual, social and technical knowledge". Instilling the knowledge of different cultures and national culture within the educational material can help students in being aware of the differences in the spiritual, social, cultural and moral behaviours from country to country which would further aid in the development of a responsible and courteous behaviour. As most of the participants confirmed in the educational field, globalization has also contributed in the field of development of teaching methodologies in Saudi Arabia. The participants put forward that the teaching methods were developed owing to globalization and it lead to the improvement of teaching and learning outcomes. The students in Saudi Arabia were already being compared with other students internationally based on certain international tests; hence globalization helped the country in formulating rules and standards in their teaching 
and testing methodologies that ensured conformance to the teaching methodologies of the developed economies. As quoted by an interviewee "Saudi Curricula have been modified to McGraw Hills". Where traditional methods involved attention of only the theoretical concepts, globalization led to an evolution in these methods by bringing in application based methodologies. Apart from the teaching methodologies, the benefits of globalization in the field of education in Saudi Arabia can be felt in the adaption, i.e. globalization has led to universal homogeneity in the field of education and students across different nations now find it easier to adjust and adapt to the university or academic standards of other nations. Globalization has also brought about waves of intellectual and cultural unification wherein the individuals are becoming more and more culturally sensitive and knowledgeable owing to the revised educational curriculum due to a globalized scenario.

\section{Negative Impact of globalization on education:}

The present study also recognized certain negative impacts on education that are likely to be caused owing to increased levels of globalization in Saudi Arabia and having discussed the various positive effects. It is imperative to shed some light on the negative effects of globalization as described by the interview participants. Judging from the results obtained from the research fieldwork, the issue that stood out in the view of the participants it sampled. Some of the interviewees believed that globalization is likely to lead to integration of foreign values as Alghathami [1] and Nurullah [16] believed that conversance is not ideal due to it opposing the teachings of the Quran. As per one of the interviewees, there is already a number of foreign schools in Saudi Arabia and this could lead to the students adopting and being attracted to the culture of another country leaving behind their own culture and ethnicity in the future. In the words of one of the interviewees "there is a fear of having ideas from the western culture" which could lead to citizens being attracted to the liberal cultures moving from own customs and values. Next, the interviewees also highlighted various challenges in terms of the curricula. As presented by one of the participant "globalization has an impact on the education plans, teaching methods and objectives, and introducing strange habits and convictions into university curricula, such as those found in English literature". This presents that the teaching methodologies that will be adopted based on the success in other countries may not be suited to own country and these may bring in ambiguity in the present course curricula instead of further improving it. Further, "The knowledge explosion will be one of the most important challenges, which will make the permanent review of the content of these curricula necessary. It is expected to threaten the principle of centralization in the writing and distribution of textbooks. Stakeholders will not be able to track the rapid changes in knowledge and methods. Teachers will also be shocked by new generation who are advanced in the use of technology". Hence, it is clear that not all the changes in the course curriculum owing to globalization are likely to be positive for the educational sector of Saudi Arab. Furthermore, not every learner is the same and different individuals have different capabilities, understanding and thought process hence; it would be difficult for those learners who require more efforts to adapt in a globalized scenario who might find it difficult to maintain their ideas and identity as a result of it. Also, the educationalists presented that globalization is being controlled by only the developed economies that are politically superior. It was presented by some that globalization is merely a means for the developed economies of spreading their culture. As presented by one of the participant "globalization have become prevalent everywhere ... and the attempt of the developed countries to shape the world by spreading concepts and theories" and one another who said that "globalization come from Western influences, whether through study in Western countries or through the diffusion of research or access to Western research and the individual's own susceptibility to change. This manifested the fear in the minds of the educationalists of losing own identity and culture in the hands of the developed countries owing to globalization.

\section{Social and cultural impact:}

Globalization in education is expected to bring varied impacts in the areas of identity, culture and thought processes of individuals that are likely to be affected by globalization. The participants presented various impacts of globalization on identity such as the fear of losing own identity, i.e. the likelihood of the citizen being more attracted to the western cultured and gradually fully moving on to the western culture leaving behind own values. As established by one of the interviewee, globalization will lead to the strengthening of citizenship but will melt down Islamic identity. One of the participant felt an example to present the same of a lady she knew "who changed her identity and immigrated to western countries and strongly refused to return home, and changed her beliefs, and believed that those Western countries had incentives to attract people". However, some participants also believed that the degree of impact of globalization in terms of losing one's identity differs from person to person and depends on their willingness to accept a change in full or maybe in part thereby also preserving one's own identity in the process. Also, the interviewees presented the different initiatives being taken by the ministry of education preserving 
the national identity such as the "lovely efforts that seek to consolidate the love of the homeland, the king and scholars and to belong to it. Also, encouraging cooperation in promoting it and teaching it in the curricula.

Establishing activities that promote religious values, fighting the inciting ideas and calling for the disintegration of society, unity and healing". The ministry is focusing on the concept (nationalization) through direct and indirect channels. It is linked to life, education and activity. Students became aware of the concept of nationalization and their role in society. Also, they are able to engage in volunteer work and participate in decision-making through educational boards and social media. In the words of one of the participant "Ministry of Education incorporates the national curriculum and consolidates the concept and themes of nationalization and pride and celebrates the National Day by several national educational activities in schools and language competitions". Quoting another view in this regard "a great effort to promote national identity through education - the national education subject - where the importance of this country and its religious value and its virtues, and the work of courses for students to consolidate the concept of nationalization, what we should do for our country". Hence, national day celebrations and national education subject can be seen as two government initiatives in Saudi Arabia in the area of preserving national identity.

Talking about the culture, there were different views presented on it from King Abdullah Project (2017) the researchers can derive the interviewees opinion in the sense of how reform is vital in terms of Saudi education quality .For instance In the words of one of the participant "the countries are now not isolated from each other, they are not isolated from the rest in the sense that the state interact with cultures of other countries and this has negative and positive sides" which reflects that cultural impact can serve to be both augmentation and deterioration for an economy. The positive impact can be felt from the fact that owing to technological innovation, culture of one economy can now easily be transferred to another. Globalization is a real cultural challenge by giving many physical and moral manifestations to the convenience of foreign language instead of Arabic. It may also lead to the spread of undesirable cultures such as the culture of luxury and extravagance, being amazed by the culture of the West, religious and personal freedoms, women's rights and spread of foreign schools.

The impact of thought process can be seen in a way that globalization has a positive effect such as acceptance of the other cultures and values, flexibility of thinking, and a negative side such as confusion of thought, and weakness of belonging.

\section{Government plans in promoting globalisation in Education:}

The participants talked about a number of ways in which the government of Saudi Arabia is attempting to ease the process of adaptation to the effects of globalization. Driven by global imperatives, therefore, Saudi Arabia has introduced many reforms into its policy. The most recent and important reform is a 2030 vision that is one of the most ambitious long-term goals. This vision supposes to lead the country to improve many aspects in the country [40]. In addition, the ministry of education has introduce Faten Program to provide protection to the values and overall beliefs as a national scheme. One of the participant stated that "Ministry of education has a great plan and have high aspirations which aims to enhance students' thinking methods, to clarify the seriousness of globalization and to put in place programs that support the rejection of globalization. Instilling pure religious and moral values, and clarifying the effects of globalization on the individual and society". In order to consolidate the national concept, the Ministry has added plans to support activities in the development strategy plans and to support activities that contribute to nationalization, such as national initiatives, voluntary work, and professional day. According to one of the participant, "The ministry of education provides a special center to follow the southern border area "Center for the support of education to the southern border" and provide follow-up plans and treatment through the compatibility of schools and the activation of e-learning". The vision 2030 and Fattan are two such initiatives in the said area by the government. The Ministry implements many projects and programmes that are rooted in the concept of nationalization such as the curriculum of national education and Fattan program and focus on rooting values and activating the national day in schools on an annual basis. As per one of the interviewee "It is a great program that makes students aware of misleading terminology and fights terrorism". However, there were also certain negative responses received on the efficacy of the Fattan program such as one of the participant saying that it is "Weak, and may be ink on paper. Projects currently released are weak and lacking in development and credibility". The vision 2030 has a role in advancing the development of the Kingdom and is a strategic plan on which every Saudi citizen depends in the area of all the changes they wish to see at all levels, first of which is education. In the words of one of the participant "We believe that what Saudi adopts in the vision of 2030 of comprehensive economic reform in all ministries is certainly the first conscious and well-informed start of its plan to meet the challenges that surround it 
with sufficient strength and elements, and that it is the vision that guides globalization in a well-planned manner in the public interest". Hence, it was felt after reviewing the responses of all the interviewees concerning the role of government, that the ministry is sufficiently addressing the impact of globalization and has developed plans to deal with the same.

\section{Contribution to knowledge:}

The present study is aimed at analyzing the impact of globalization on the educational sector of Saudi Arabia. While there have been various studies that have studied globalization in relation to various other variables such as economic growth, cultural impact, cross cultural communication etc. There has been limited literature exploring its impact on the educational sector in the Saudi Arabia. Hence, this study would be an attempt to recognize the same.

It is expected that this study will make a significant contribution to the knowledge, where it is concuring with leading the change that has taken place by the gorvernment in Saudi Arabia to reform education and society. It also includes diverse perceptions and views of this change. These diverse perspectives are important to understand the shift in the policy and practices in the Saudi Arabian context.

\section{Conclusion:-}

The findings generated from this study provide information about how globalization affects Saudi Arabia's educational structure. The results show that the globalization has shown both its good and bad sides. It is clear that participants witnessed several advantages in terms of globalization as they confirmed it making the world more connected and informed than ever before, not forgetting that it wasn't a form of cultural exchange but rather an experience swap, it brought ways of learning from universal practices to improve the student outcome. However, due to it being internationally sourced it leads to slight difficulties when it came to integrating students. Moving on, the downside was that the participants feared of the loss of individual culture, one's identity, and the chance of exploitation. Most importantly the new strategy of learning methods has its difficulties in terms of applicability, it may suite one school in one part of the world and however it may not in another. The more developed a country is the higher their cultural effect becomes, as a result of that the Saudi ministry of education works to absorb the foreign impact while protecting their own culture, heritage and values by supporting activities and projects that can contribute to nationalization to lead to a better world for the new generation.

\section{Author Contributions:}

Conceptualization, R.A.; data curation, R.A. and N.Aj.; writing—original draft, R.A., N.Aj., and A.A.; writingreview and editing, R.A.

\section{Funding:}

This research received no external funding.

\section{Conflicts of Interest:}

The authors declare no conflict of interest.

\section{References:-}

1. Alghathami, M., Neoliberal: Questions in negotiating freedom and cultural. 2013, Aldar Albaidha: The Cultural Arabic Center

2. Dyer, S., et al., Understanding Management Critically: A Student Text 2014, London: Sage.

3. Scholte, J.A., The Sources of Neoliberal Globalization. 2005, Geneva United Nations Research Institute for Social Development (UNRISD)

4. Mrak, M., Globalization: Trends, Challenges and Opportunites for Countries in Transition. 2000, United Nations: Industrial Development Organization: Vienna.

5. Adams, F.G., Globalization, Today and Tomorrow. 2011, New York: Routledge.

6. Held, D., et al., Global Transformations: Politics, Economics and Culture. 1999, Cambridge: Polity Press.

7. Giddens, A., The Consequences of Modernity. 1990, Stanford: Stanford University Press.

8. Robertson, R., et al., Globalization, Wages, and the Quality of Jobs. 2009, Washington The world bank.

9. Kotz, D.M., Globalization and Neoliberalism. Rethinking Marxism 2002. 12(2): p. 64-79.

10. Saad-Filho, A. and D. Johnston, Neoliberalism: A critical Reader 2005, London Pluto Press.

11. Spence, M. and D.M. Leipziger, Globalization and Growth: Implications for a Post-Crisis World. 2010, Washington, D. C: The world Bank. 
12. Corak, M., Income Inequality, Equality of Opportunity, and Intergenerational Mobility. Journal of Economic Perspectives, 2013. 27(3): p. 79-102.

13. Alnajem, M., Woman poverty characteristics in the Saudi Societies, in Social scinces. 2012, King Saud University: Riyadh

14. Aksornkool, N., Educate to Empower: An Asian Experience in Women, Education and Empowerment: Pathways towards Autonomy. Report of the International Seminar held at UIE, Hamburg, 27 January - 2 February 1993 , C. Medel-Anonuevo, Editor. 1995, UNESCO Institute for Education. p. 53-61.

15. Spring, J., Globalization of Education: An Introduction 2009, New York: Routledge.

16. Nurullah, A.S., Globalisation as a Challenge to Islamic Cultural Identity. The international Journal of interdisciplinary social sciences, 2008. 3(6): p. 45-52.

17. Burbules, N.C. and C.A. Torres, Globalization and Education: Critical Perpectives. 2000, Great Britian Routledge.

18. UNESCO, Teaching and Learning: Achieving quality for all. Education for All Global Monitoring Report - $2013 / 4$. 2014, UNESCO

19. Elyas, T. and A. Al-Sadi. Critiquing of Higher Education policy in Saudi Arabia: A Neoliberalism Approach. in The Asian Conference on Language Learning 2013. 2013. Osaka, Japan: The Asian Conference on Language Learning 2013: Official Conference Proceedings.

20. Carnoy, M., Globalization and educational reform: what planners need to know 1999, Paris UNESCO.

21. Misra, S. and A. Bajpai, Implications of Globalization on Education. 2010, India: Rameshwaram Institute of Technology \& Management.

22. Stronach, I., Globalization Education, Educating the Local How method made us mad. 2010, New York: Routledge

23. OECD, What is PISA? 2014, PISA 2012 Results: What studnets know and can do (Volume 1, Revised edition, February 2014): Student Performance in Mathematics and Science. OECD Publishing. Available on http://dx.doi.org/10.1787/9789264201118-en.

24. Murphy, S., The Pull of PISA: Uncertainty, Influence, and Ignorance. RIED IJED International Journal of Education for Democracy, 2010. 3(1): p. 27-44.

25. Rugh, W., Arab education: Tradition, growth and reform. The Middle East, 2002. 56(3): p. 396-414.

26. Prokop, M., Saudi Arabia: The Politics of Education. In International Affairs (Royal Institute of International Affairs 1944-), 2003. 79(1): p. 77-89.

27. Pennycuick, D., School effectiveness in developing countries - A summary of the research evidence - Education Research Paper. Centre for International Education University of Sussex, 1993. 1.

28. Bruns, B., D. Filmer, and H.A. Patrinos, Making Schools Work. 2011, Washington: The World Bank.

29. Bangs, J., J. MacBeath, and M. Galton, Reinventing Schools, Reforming Teaching: From Political Visions to Classroom Reality. 2011, London and New York: Routledge.

30. Morley, L. and N. Rassool, School Effectiveness: Fracturing the Discourse. 1999, London and New York: RoutledgeFalmer

31. Levin, B., Reforming Education from Origins to Outcomes 2001, London: Routledge Falmer.

32. Haddad, W.D., et al., Education and Development: Evidence for New Priorities World Bank Discussion Papers 95. 1990

33. Harris, A., et al., Effective leadership for school improvement. School leadership series. 2003, London: RoutledgeFalmer. ix, 201.

34. Sahlberg, P., Education policies for raising student learning: the Finnish approach. Journal of Education Policy, 2007. 22(2): p. 147-171.

35. McLaughlin, M. and M. Rouse, Special Education and School Reform in the United States and Britian. 2000, New York: Routledge.

36. King Abdulla Bin Abdul-Aziz Project for Public Educational Development, 2011. King Abdulla Bin Abdul-Aziz Project for Public Educational Development, ed. T. Project. Riyadh: King Abdulla Bin Abdul-Aziz Project for Public Educational Development.

37. Hopkins, D. and B. Levin, Government policy and school improvement. School Leadership and Management, 2000. 20(1): p. 15-30.

38. Hopkins, D., et al., School and system improvement: State of the art review. In International Congress of School Effectiveness and School Improvement, Limassol, Cyprus, 6th January, 2011.

39. Braun, V. and V. Clarke, Using thematic analysis in psychology. Qualitative Research in Psychology, 2006. 3: p. 77110.

40. Alamrai, M. what does the vision mean? 2016 [cited 2018 available atArticle Globalization and its implication on education in the context of Saudi Arabia.docx 14 August]. 